\section{SHIP BERI-BERI.}

Bx GEORGE A. TURNER, M.B., D.P.H., Medical Officer of Health for Kimberley, Bouth Africa.

WHILE carrying on the work of Additional Port Health Officer for Table Bay, it was my duty to board and examine all vessels before they were granted pratique. During the fifteen months I was thus employed I came across a number of cases of the type of the disease known as ship beri-beri.

\section{SYMPTOMS.}

As my duties merely consisted in the diagnosis of disease and the superintendence of subsequent precautions, it will be understood that I neither speak from personal experience of the course of the disease nor its treatment. I will therefore merely enumerate some of the principal symptoms which I noticed :

x. Oedema.

2. Irregularity of the heart's action.

3. Paralysis of very varying degrees.

4. Tenderness of the calves.

5. Irregularity of the knee-jerks.

My experience with regard to crews and passengers suffering from beri-beri was as follows: On boarding a vessel I was told that there were one or two men sick ; in many cases the captain or chief officer stated at once that the men had beriberi, and I would be shown one or two men lying in their bunks with well-marked symptoms and apparently extremely ill. Such cases were plain sailing, but when I endeavoured to ascertain whether the other members of the crew were in any way affected matters became more difficult. As a rule they all (being in port) declared themselves quite well, and it was only after careful examination of each individual that $I$ was in a position to estima te the extent of the outbreak.

Generally, if one or two of the crew were laid up in their bunks with marked beri-beri I found several others in the earlier stages of the disease. The symptoms I looked for were: (1) Rapidity of the pulse, (2) oedema of the ankles.

Wherever marked cases of beri-beri existed on board a ship I considered the presence of these indications sufficient to justify me in putting a man down as suffering from the disease.

As regards the knee-jerks, I may say that I attached no particular reliance to them. I have seen them exaggerated in some cases, absent in some, and, again, in others quite normal. In advanced or acute cases the walk was characteristic.

I have seen cases amongst Indians, and Europeans as well, which were so slight that the men were able to carry on their ordinary duties as seamen, and they would not believe they were sick. On the other hand, I have seen Chinamen in the hold of a ship who were absolutely unable to move.

The following extract of notes taken from one vessel may be of interest :

A barque which left Rangoon at the end of May, 1903 arrived in Capetown in August of the same year, she had carried deals from the Baltic to Delagoa Bay, where she lay five or six weeks, and had then sailed to Rangoon. Her original crew consisted of sixteen men; of these, two deserted at Delagoa Bay, one died of the disease between that port and Rangoon, and three were left in hospital at Rangoon, so that fresh hands had to be engaged for the return voyage. Between Delagoa Bay and Rangoon all the crew were infected with the exception of four hands, namely, the first mate, carpenter and two boys.

On her arrival in Table Bay all were again infected, with the exception of six, so that there were 1o cases, several of whom were evidently relapses of the sickness contracted between Delagoa Bay and Rangoon. I may here mention that Norwegian and Swedish sailors frequently stated they had suffered from the disease on more than one occasion. The most prominent symptoms on this vessel were oedema of the legs and peculiarity of the heart's action, the kneejerks were absent in most of the instances, though present in some ; in one they were exaggerated; one or two of the patients had discoloured gums.

Before leaving this very brief account of the symptoms, I will relate two other cases which occurred on a Russian boat which are of interest because they tend to show that the severity of the symptoms is not a guide to the prognosis.

When the vessel on which these two cases occurred arrived in Table Bay the first officer reported that the captain had died some fourteen days previously (doubtless, from the description given, of beri-beri), he further reported that the crew had contracted scurvy. I examined the cases of alleged scurvy and found them to be undoubtedly beri-beri. The worst case appeared to be the steward. This man had oedema from the feet to the abdomen, his scrotum was tremendously swollen, and there was evidently some fluid in the chest, the action of his heart was irregular and rapid, and I formed the opinion that the man would die. When I came to examinethe rest of the crew I found most of them had some rapidity of the heart's action, with slight oedema of the ankles. These men were doing ordinary seamen's duties, and were not, as far as one could see, in a dangerous state, but one of them died within a day of my examination, whereas the steward, to my surprise, recovered completely.

\section{ETIOLOGY.}

After the diagnosis this is naturally the part of the subject which, as port officer, concerned me most, and the following are briefly the conclusions at which I arrived :

1. That no probability attaches itself to the theory that ship beri-beri is caused by want of ventilation.

2. That equally small reliance is to be placed in the diet and metal poisoning theories.

3. That the evidence tends to support the theory of $\mathrm{Sir}$ Patrick Manson that beri-beri is a place disease, and also that it is a germ disease, but probably not communicable from man to man; further than this I cannot go, but it may be noted that in Sir Patrick Manson's opinion the germ does not live as a parasite in the human body, but possibly the disease is caused by a toxingenerated by a germ living in the patient's surroundings.

The history of the infected ships I boarded, and also information which I gathered from captains of other Norwegian vessels, generally intelligent men, who in the course of a long seafaring life had seen much of the disease and knew it well, may be summed up as follows: Small wood barques from the Baltic, manned chiefly by Scandinavian or Russian sailors, would leave with a cargo of deals (light wood, so that they carried a big deck cargo) for an East African port; there they would go up a river, and discharge cargo and take in wet sand ballast. After lying in the river some weeks they would sail for an Indian port-say, Rangoon-and there take in a cargo of teak, a heavy wood, wet and slimy from soaking. in the water, and the vessel would sail for some European port. On account of the heaviness of the wood no deck cargo could be carried. The important point, to my mind, in these histories is that cases of beri-beri apparently do. not occur on the voyage from the Baltic to the East Coast; at all events I have not heard of one-that. is to say, that while the ship has a deck cargo, which, rising above the level of the roof of the deck-house, surrounding it with a coating of wet wood, preventing ventilation and of necessity making the crew's quarters very damp, and while, for a period at any rate, the weather is cold, so that probably all doors, ports, etc., are kept closed, to the further exclusion of fresh air, no cases of beri-beri happen On the other hand, soon after a ship leaves the East Coast in vallast-that is, when she is light and has dry decks and the deck-house is well ventilated - the disease will sometimes make its appearance, though more frequently it does not break out until a ship leaves the Indian port, when the deckhouse is again clear and is well ventilated. Again, I noticed that the officers on these infected vessels had quite as large a number of their mess attacked with the disease as the ordinary seamen, and their quarters contained a larger cubic capacity per head than that of the seamen's.

These facts, coupled with statements to be referred to later on, seem, in my judgement, to be contrary to the theory that want of ventilation and atmospheric dampness are in themselves the cause of the disease, because it is always when the men's quarters are welk ventilated that the trouble occurs.

Diet and Rice Theory.

Various peculiarities of diet have at times been put down as the cause of the disease. Rice has been particularly mentioned. My small experience at Cape Town certainly did not support this theory, as the majority of the sufferers were Scandinavians-well-nourished sailors, properly fed on meat, vegetables (compressed when long at sea), bread or biscuits-who, I do not suppose, had any rice at all in their rations.

On the other hand, thousands of Indian coolies have passed through my hands in Table Bay, whose principal diet was rice or nuts. Yet I did not see a single case of the disease 
among the Indian immigrants, and only very few among the lascar crews; two cases of the latter I shall refer to presently. At the same time I had several cases among Chinese passengers who fed on far better diet than the Indian coolie; but these Chinese in two vessels had only come a short voyage from Mauritius, and had possibly contracted the disease before embarking.

\section{Metal Poisoning.}

This has been suggested as a cause of beri-beri; some captains of vessels are firmly convinced this is so. On more than one occasion I have been asked to see some tins of meat opened to give an opinion on them. Possibly the theory is due to cases of metal poisoning having been mistaken for beri-beri. It is not at all unlikely that rations may become contaminated with metals, especially now that tinned foods are so largely used; and the question of metal water tanks, too, must be remembered.

\section{Toxic Theory.}

The facts, as I have observed them, do not support the ventilation or diet theory, but rather favour the theory that the disease is caused by the absorption of a toxin formed by an organism outside the body.

I have given a good deal of careful consideration to the cases I have met with, and it seemed to me possible that the organism or origin of the disease, whatever it may be, might exist in the water and mud of tropical rivers, not necessarily in the drinking water, and that infection in the case of shipping was taken on board with the wet wood cargoes or the wet sand ballast, anchors, and cables, so that when the crew for any reason were rendered susceptible to the poison, either on account of being run down from fever, hard work, sudden change of climate, or from sickness of any kind, the disease manifested its presence.

First, I noticed that the small barques which were infected generally discharged their light cargoes at tropical or subtropical ports, and then took in wet sand ballast, and, of course, at the same time drinking water.

In the case of ships which had sailed from Rangoon I found that the timber taken in had been soaking for some considerable time in water, and the fact that the crews of wood vessels seemed most liable to the disease, combined with other factors, led me to suspect the wet-sand ballast and wet logs as the cause of the trouble. It is after a vessel leaves Rangoon that the disease most usually makes its appearance; possibly Rangoon is more highly infected than East African ports. Vessels coming to Table Bay for assistance usually stated that the first case occurred ten to twenty days out from port, but at the same time I was told that, as a rule, it was not until the ships crossed the line and encountered cold weather that the disease made its appearance.

I account for the various periods at which the disease breaks out after leaving port in this way: In the case of vessels in which the disease breaks out only ten days after sailing the crew may have been run down at starting by malaria, or possibly by the drunken debauch which sometimes precedes departure from port, and they may on these accounts be more susceptible to the action of the poison.

On the other hand, cases in which the disease does not appear for a month or more after sailing may be due to the fact that the crew started in good health, and time was required for the virulence of the poison to increase before making itself felt, or the sailors may become more susceptible after crossing the line, owing to change of temperature, excessive work through bad weather, or the want of fresh food.

The captain of one of these vessels informed me that beriberi was endemic among the population at Rangoon who lived on the sea coast, that is, among lighthouse keepers, fishing populations, etc., whereas people living a little inland were free. This statement would also point to infection being obtained in some way from the water. However, I observe on referring to Scheube's map that the whole of Burmah is there marked as affected. The case of the two lascars before referred to as suffering from the disease on a steamer from Bristol, one of whom died, the other man having been treated for supposed Bright's disease at Bristol, and having evidently been sick for some time, may appear to be an exception to my previous statement. But it is significant that the boat came from an Indian port to Bristol, and further, she had an old-fashioned forecastle, so that the cable came through the hawse-pipe into the men's quarters, bringing up a quantity of mud and water when the anchor was raised, which in itself might suffice to produce the toxin, as the mud and water would spread over the deck of the whole forecastle, and, in the case of an old vessel, get between the seams of the deck planks; it would certainly not be removed by even careful scrubbing, and the deck of the forecastle is not over-carefully scrubbed.

Outside the marine population, as far as South Africa is concerned, cases of the disease chiefly occur among the Chinese. The peculiar liability of the Chinese race to beriberi might be accounted for by the fact that the victims have come from infected marshy districts in China, and, having suffered from the disease previously, are liable to relapse or are more susceptible to the toxin. I have seen a case of the disease in Johannesburg, and a medical man there told me that he had had about a dozen other cases among Chinamen. Now, though Johannesiourg is highly situated, it has a swampy portion, and the Chinese seem to congregate round the swampy area, which is waterlogged, and which may be infected with the disease. I do not suggest that the limited evidence $I$ have cited is conclusive, but it seems to me perfectly consistent with Sir Patrick's Manson's theory as far as it goes.

I had no opportunity of studying the pathology or treatment of the disease, but one thing I noticed was that some of these wood barques of which $I$ have been speaking were actually supplied with several gross of capsules containing iron and extract of bone marrow for the treatment of beriberi, which shows that the captains of these vessels expect in the course of the voyage to be attacked with the disease.

Further, from the account of a Norwegian captain, some vessels are more prone to infection than others, one vessel of which I obtained a history had cases of beri-beri on four voyages out of five. Unfortunately, my notes made at the time are missing, and I cannot give full details, but it seems to point to the vessel having at some time received more infection than usual, so that the virulence of the toxin was continually being augmented; thus, when an opportunity offered, the poison made itself manifest by an outbreak of the disease.

\section{NOTES ON CASES OF SPIRILLUM FEVER IN UGANDA.}

\author{
AOBREY D. P. HODGES, and PHILIP H. ROSS, \\ M.D.Lond \\ Uganda \\ M.R.C.S., L.R.C.P., D.P.H. \\ Protectorate. \\ Uganda.
}

ON October 23rd, 1903, in examining a blood film from an Indian, spirilla were found scattered eparsely through the slide, one occurring in about fifteen to twenty fields. They stained blue with Leishman's stain, were sharply pointed at both ends, varied in length between $36 \mu$ and $42 \mu$, and were about $4 \mu$ in diameter.

As up to this time no case of spirillum fever had been recognized as such or recorded in Uganda, a special interest attached to this discovery. Moreover, the patient being an Indian, the question arose whether he could have brought the infection from his own country, butas he had been over a year resident in Uganda this was not deemed likely. He was first seen on the morning of October 23rd, having been taken ill only the night before. There was no history of a previous attack. His condition when seen was as follows:

He was a small, poorly-nourished man of about $30 ;$ his temperature was ro3. $4^{\circ}$; he was prostrate, anxious, vomiting continually a greenish vomit, and complaining much of pain in the epigastrium and the small of the back. He also had a rather severe headache and pains in the limbs. There was slight tenderness over the liver and spleen and some slight enlargement of the latter. The urine was febrile, and contained nothing abnormal. In the afternoon his temperature was still over ro $3^{\circ}$, and the next morning it was normal, having fallen in the small hours apparently by crisis. In blood flims taken the next morning no spirilla could be found. He complained then of nothing but weakness, and in anuther day was at work again.

On November 1 ith - the nineteenth day-the patient had a relapse almost exactly resembling in symptoms and duration the first attack, and spirilla were found in both fresh and stained specimens of blond. $\Lambda$ few drops of blood from the finger-tip were drawn off with the usual precautions into I per cent. solution of potassium citrate, and the mixture injected subcutaneously into a monkey (Cercopithecus).

The following results occurred :

On November 16 th, three and a half days after inoculation, the monkey's morning temperature was $105.6^{\circ}$, and numerous spirilla were 